\title{
Erratum to: Gendered support to older parents: do welfare states matter?
}

Tina Schmid • Martina Brandt • Klaus Haberkern

Published online: 3 May 2012

(C) Springer-Verlag 2012

Erratum to: Eur J Ageing

DOI 10.1007/s10433-011-0197-1

In the published article, Fig. 5 was incorrect. The corrected

figure appears in this erratum.

The online version of the original article can be found under doi:10.1007/s10433-011-0197-1.

T. Schmid $(\bowtie) \cdot$ K. Haberkern Institute of Sociology, University of Zurich, Andreasstrasse 15, 8050 Zurich, Switzerland

e-mail: schmid@soziologie.uzh.ch

M. Brandt

Munich Center for the Economics of Aging (MEA),

80799 Munich, Germany 


\section{Sporadic support}
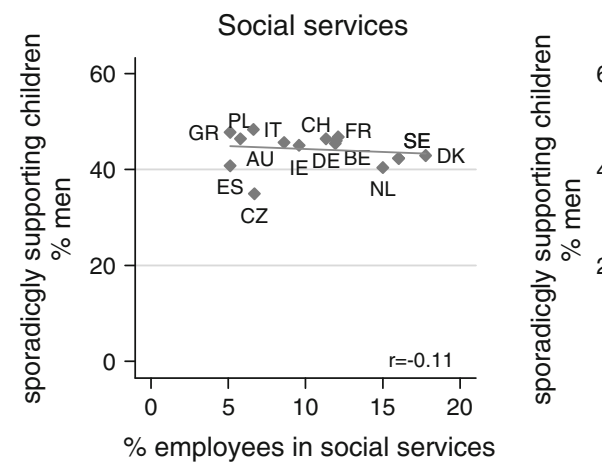

Cash benefits
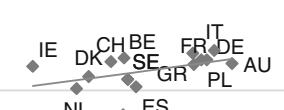

$\mathrm{CZ}$

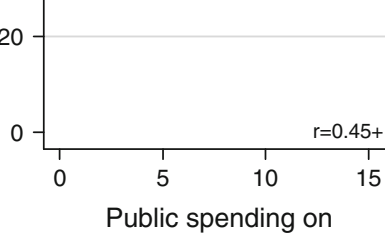

cash benefits in \% of GDP

Intensive support

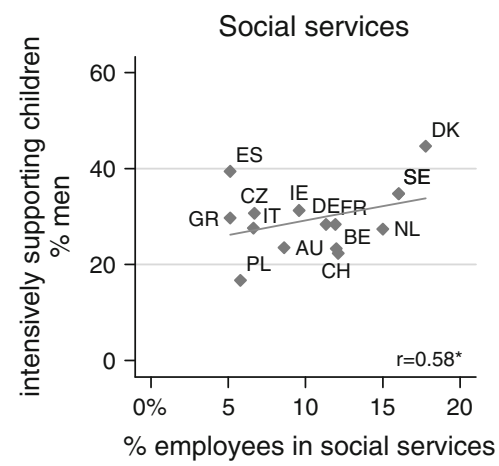

Cash benefits

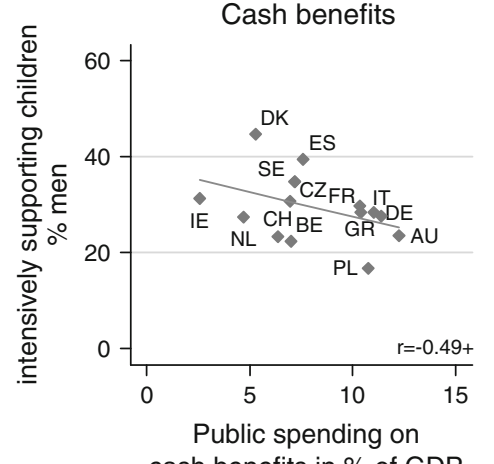

Legal obligations
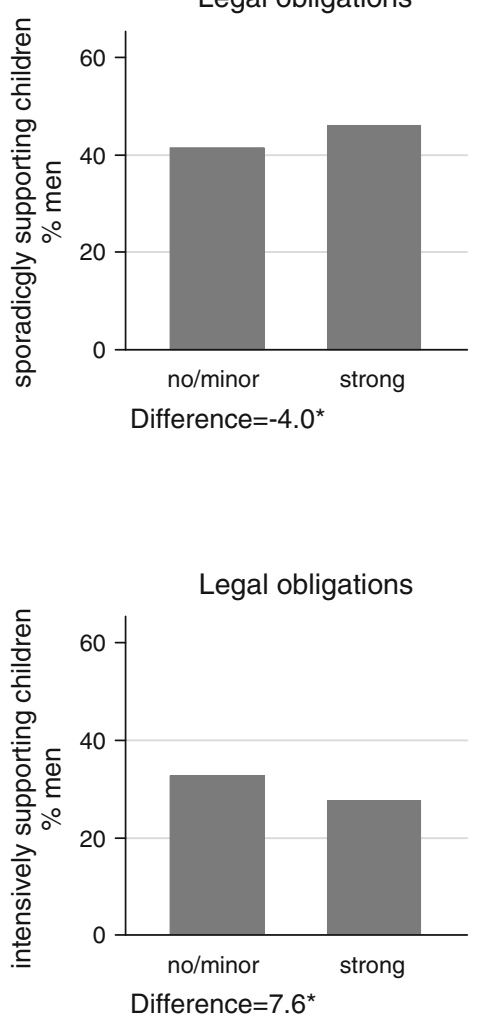

Fig. 5 Gender compositions of children supporting a parent and the welfare state. Source SHARE 2004, 2006, respondents 50+ who sporadically $(n=2,824)$ or intensively supported a parent $(n=774)(n<30$ in IE, CH, DK). OECD (2010), Mestheneos and
Triantafillou (2005). Significance levels ${ }^{+} p<0.1 ; \quad * p<0.05$; $* * p<0.01 ; * * * p<0.001$. Own calculations, weighted. Coefficients reported: Pearson correlation coefficients respectively $t$ test (legal obligations) 